\title{
A Modified Elastic Plate Model for the Thickness of Reinforced Soil of Shield Tunnel End
}

\author{
Yi Song ${ }^{1, a^{*}}$ \\ ${ }^{1}$ School of Civil engineering, Beijing Jiaotong University, Beijing 100044, China \\ ayisongbjtu@126.com
}

Keywords: Shield tunnel; Soils of tunnel end; Reinforced thickness of soil; Modified elastic plate model

\begin{abstract}
Object: This paper is concentrated on soil body's stability and economy of the shield end and its reinforced thickness.

Methods: Existing elastic thin plate model was too conservative for design. A modified elastic plate model of the thickness was proposed for calculation. Based on elastic finite element analysis data, optimal fitting was carried out for the proposed elastic model. and the coefficients of the model were obtained.

Results: The maximum bend stress of the model of elastic thin plate is higher than that of the modified model of elastic plate. It has been manifested by the calculations. The model of elastic thin plate is more conservative and its degree is determined by the ratio of thickness to diameter of the plate $(t / D)$. The finally value of the thickness in practice is between the value of elastic thin plate model and the value of modified elastic plate model.

Conclusion: It has proved that the suggested model is useful for engineering practices, and extends theoretical methods for calculating the reinforced thickness. In engineering practices the model of elastic thin plate and the modified model of elastic plate should be used to calculate the reinforced thickness synthetically.
\end{abstract}

\section{Introduction}

With the development and upgrade of infrastructures, shield method is widely used in construction of city tunnel and underwater tunnel. During the construction of shield tunnel, diaphragm wall of the tunnel end shaft must be broken when shield launching and shield arriving which lead to the soil collapse of the end easily. This is a high risk work during the construction the shield tunnel. A case of ground surface collapse and fracture at the shield tunnel end is shown as Fig.2 which is due to breakage of the diaphragm wall and the instability of the end soils. Then an analysis and evaluation of the end soils and subsequent soils reinforcement is significant to the shield launching and arriving. It concerns the key of the shield tunnel construction.
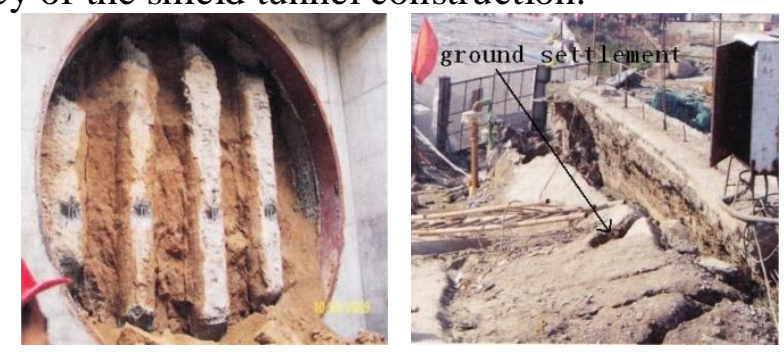

Figure 1. Diaphragm wall breaking and ground surface collapse of a shield tunnel end soil

Generally, issues of the shield tunnel end soil can be divided into soils failure mode, soil stability, reinforced range, reinforcement methods and reinforcement strength, etc[1-3]. Based on the practical conditions and the experiences of previous engineering, there are mainly several viewpoints concerning reinforced thickness of the tunnel end soils(as shown in Fig. 2): (1) reinforced thickness of the tunnel end soils are all $6.0 \mathrm{~m}$ no matter how long main machine of the shield is; (2) reinforced thickness of the tunnel end soils is $3.0 \mathrm{~m} \sim 3.5 \mathrm{~m}$ concerning existing of 
waterproof board at the hole door and combined action of the shield and the waterproof board; (3) when the shield tunnel is below the groundwater table, reinforced thickness of the end soils should be sum of length of shield main machine and cover thickness(generally $1.5 \mathrm{~m} \sim 2.0 \mathrm{~m}$ ). Concerning the property of ground, there are experiences about the reinforced thickness. When the shield tunnel is located in cohesive soils, the reinforced thickness is taken as $3.5 \mathrm{~m}$ generally. When the shield tunnel is located in sandy soils, one method is the sum of length of shield main machine and cover thickness(generally $1.0 \mathrm{~m} \sim 1.5 \mathrm{~m}$ ), another method is also taken as $3.5 \mathrm{~m}$, but double liquid grouting at the shield tail must be developed synchronously.

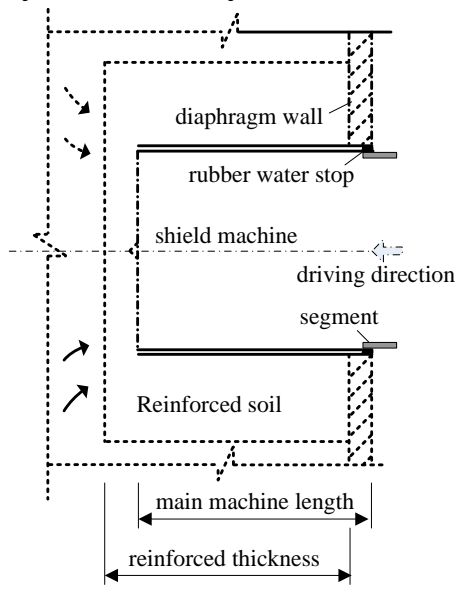

Figure 2. Thickness of reinforced soil of shield tunnel end

Reviewing domestic and international development, the related researches on the stability and the reinforced thickness of the tunnel end soils are mainly from: (1) theory of whole plate model in code of Japan Association of JET GROUT(JJGA)[4], in which the reinforced soil is supposed as a whole elastic plate; (2) theory of soil slip instability in Japan[5], in which a mass sliding mode of the soils is supposed and a combined slip face of line and arc is assumed to calculate slipping moment, and used to analyze the stability of the end soils. Based on the theory of soil slip instability in Japan, J.M. Lai and Y. Bai[5] develops numerical simulation of soft soil's stability in Shanghai using 3D nonlinear finite element method, and develops a combined slip face of line and arc of the end soils. Working on the soft soil layer in Shanghai, $\mathrm{D}$. Wu[6] analyze strength and stability of the reinforced body based on the model of document [4-5], and a comprehensive method is developed to calculate the reinforced range of the end soils. Subsequently, stress distribution and deformation law of the reinforced body are also simulated by FEM when the shield is launching. A combined slip mode of vertical line and declining line is developed by L.M. Yin[7] when he research the problem of reinforced soils of sandy pebble, and the mode is used to calculate the reinforced thickness of the end soils. Based on the former researches, a comprehensive and detail study on the failure and reinforcement of the end soils is carried out by Y.S. Jiang and F.R. Luo[1,8]. A mechanic model of equivalent load is proposed to carried out theory and engineering study on the strength and reinforced thickness of the tunnel end soils. In order to find out the relationship between reinforced range and reinforced effect, a numerical simulation model is built to analyze pre-reinforcement range of the shield tunnel end by Z.S. Xin[9-10]. Then the reinforced range is adjusted to achieve desired results which provides a scientific reference for the problem of the reinforced range of the tunnel end. For the sake of Nanjing metro tunnel construction, researches on reinforced range, reinforced strength and waterproof requirements are developed by X.P. Hu and M. Sun[11]. Then a reinforcement mode for the special sandy ground in Nanjing is proposed to the tunnel end. In view of domestic shield tunnel construction, the empirical values of reinforced thickness and reinforced width of the end soils are introduced, the strength and the stability of the end soils are checked by means of existing theoretical method. For the problems of reinforcement of the end soils, a library of reinforcement plans of the end soils is built by S.Y. Zhu and Z.B. Lin[12]. Based on the plan library, the stability of the end soils can be inferred and the reinforcement plan and measures can also be advised according to the specific engineering conditions. Based on the 
above researches, a limit equilibrium model of combination of decline line and logarithmic spiral is developed by K.Z. Song and M.S. Wang[1-2], and applied for calculation of reinforced thickness of the end soils, better results is gained in the practice.

With the development of shield tunnel technologies in China, the above researches have played an important role in exploring failure mode of the end soils, calculating reinforced thickness, guaranteeing stability of the soils. But engineering accidents happens frequently in shield tunnel construction and it may be related to the ground properties and corresponding reinforced thickness of the end soils. In order to ensure the soil's stability the end soils must be reinforced in a determinate range. But the reinforced thickness cannot be too large, or else it is unfavorable for shield driving and engineering economy. In order to further discuss more scientific and reasonable calculation model for the reinforced thickness of the soils, a modified elastic model will be developed in the paper based on elastic thin plate model.

\section{Modification of Elastic Thin Plate Model}

Elastic Thin Plate Model. The reinforced thickness of the end soils is calculated by the model of elastic thin plate in Japan[4]. It assumes that reinforced body is a elastic thin plate simply supported peripherally and resisting soil pressure and water pressure as shown in Fig. 3. The pressure of $p_{0}$ is equal to the sum of the maximum of $p_{\mathrm{s}}$ and $p_{\mathrm{w}}$. This model is mostly used to calculate the reinforced body thickness theoretically in the world currently[1,6,7,8,10-12].

According to the model of elastic thin plate, the maximum bend stress at the plate center is expressed as follows

$$
\sigma_{\max }=\frac{3(3+\mu) p_{0}}{32} \cdot\left(\frac{D}{t}\right)^{2} \leq \sigma_{t}
$$

Where, $\mu$ is poison ration of the body, $p_{0}$ is unit uniform load vertical to the body face, $D$ is diameter of the circular plate, $t$ is the plate thickness, $\sigma_{\mathrm{t}}$ is ultimate tensile strength of the reinforced soils. Considering the engineering safety factor is $K_{0}$, the thickness of the elastic plate can be derived by 1 as follows

$$
t=K_{0}\left[\frac{3(3+\mu) p_{0} D^{2}}{32 \sigma_{t}}\right]^{\frac{1}{2}}
$$

Modified Elastic Plate Model. Considering the thickness of plate, if the ratio of the thickness to the minimum feature size along the plane is greater than $1 / 5$, it can be defined as thick plate; if the ratio of the thickness to the minimum feature size along the plane is between $1 / 80$ and $1 / 5$, it can be defined as thin plate[13-14].

In the model of elastic thin plate, shear deformation and normal stress are neglected. This is a plane stress condition and there is not interactive compression among every thin layers parallel to the neutral layer in the plate. If the size of the plate is within the thin plate definition, the elastic thin plate model can give a reasonable result generally. But it becomes more conservative to thick plate. To the problem of thick bend, mathematical solution is more trouble, series solution or elastic FEM solution is used.

The reinforced thickness of the tunnel end soils varies with different engineering methods. In general, the reinforced thickness are relatively thinner because of its more high strength built by freezing method. However the reinforced thickness are more larger reinforced by jet grouting pile and mixing pile. Whatever reinforced methods, the reinforced thickness are all in the range of thick plate.

In order to modify the model of elastic thin plate and explain the feasibility of the modified model, elastic FEM analysis is launched to plates of different thickness. Considering frequently used sizes of plate thickness, the ratios of plate thickness and plate diameter are distributed in 0.1 and 1.0 in the FEM model. Boundary condition of the elastic plate is peripheral simple support. The 
FEM parameters are determined by means of engineering practice, where elastic modulus $\mathrm{E}=100 \mathrm{MPa}$, poison ratio $\mu=0.25, \mathrm{p} 0=1.0$. The numerical model is as shown in Fig. 3. Then maximum bending stress at the plate center of all the cases are solved out. The results of both models are compared as shown in Table 1.
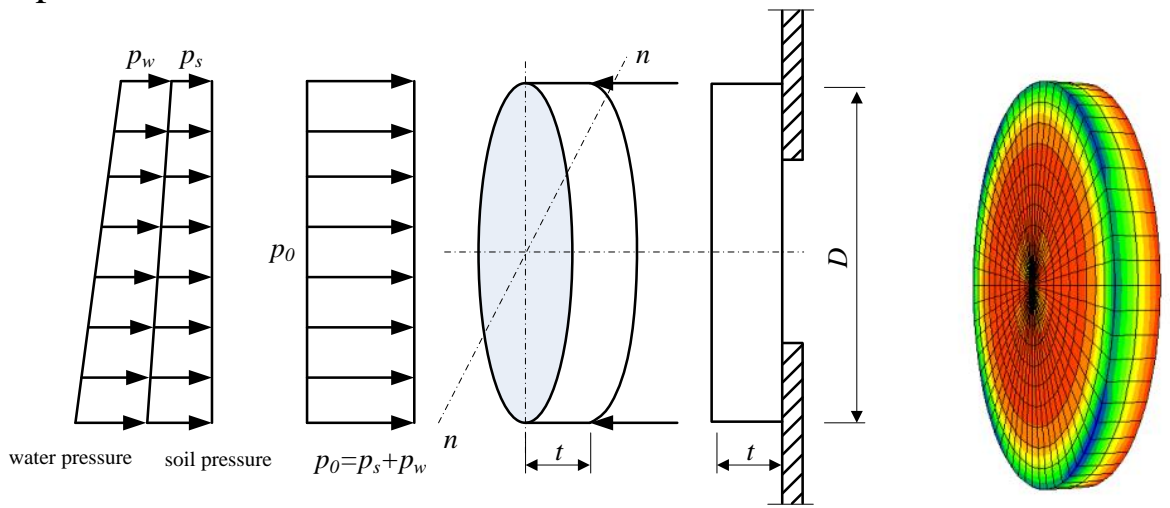

Figure 3. Elastic plate model and numerical model of thickness of reinforced soil of shield tunnel end

Table 1 Comparison between elastic thin plate model and FEM(Maximum bending stress at the plate center)

\begin{tabular}{|c|c|c|c|}
\hline$t / D$ & $\begin{array}{l}\text { Solution of } \\
\text { elastic thin } \\
\text { plate } \\
\text { model[MPa] }\end{array}$ & $\begin{array}{l}\text { Solution of } \\
\text { FEM[MPa] }\end{array}$ & $\begin{array}{l}\text { Safety } \\
\text { degree }\end{array}$ \\
\hline 0.10 & 30.47 & 12.18 & 2.50 \\
\hline 0.15 & 13.54 & 5.67 & 2.39 \\
\hline 0.20 & 7.62 & 3.39 & 2.25 \\
\hline 0.25 & 4.88 & 2.01 & 2.44 \\
\hline 0.30 & 3.39 & 1.32 & 2.56 \\
\hline 0.35 & 2.49 & 0.91 & 2.74 \\
\hline 0.40 & 1.90 & 0.63 & 3.03 \\
\hline 0.45 & 1.50 & 0.54 & 2.80 \\
\hline 0.50 & 1.22 & 0.46 & 2.64 \\
\hline 0.55 & 1.01 & 0.38 & 2.66 \\
\hline 0.60 & 0.85 & 0.32 & 2.64 \\
\hline 0.65 & 0.72 & 0.29 & 2.47 \\
\hline 0.70 & 0.62 & 0.28 & 2.20 \\
\hline 0.75 & 0.54 & 0.28 & 1.97 \\
\hline 0.80 & 0.48 & 0.26 & 1.81 \\
\hline 0.85 & 0.42 & 0.25 & 1.72 \\
\hline 0.90 & 0.38 & 0.24 & 1.59 \\
\hline 0.95 & 0.34 & 0.22 & 1.52 \\
\hline 1.00 & 0.30 & 0.21 & 1.45 \\
\hline
\end{tabular}


Based on engineering experience[1,11,12], the values of $t / D$ of the model in Tab.1 extend most reinforced sizes in common construction methods. As shown by the calculated results, the bend stress of the elastic thin plate model are more larger than that of FEM. Therefore the theory of elastic thin plate is too conservative to calculate the reinforced thickness and the conservative degree varies with the value of $t / D$.

Then according to the elastic FEM analysis data, the existing elastic thin plate model will be modified.

According to Eq.1 of elastic thin plate model, the calculation formula for the maximum bend stress at the plate center is set as follow

$$
\sigma_{\max }=k \cdot p_{0}\left(\frac{t}{D}\right)^{\alpha}
$$

where, $k$ is a synthetic coefficient containing poison ratio, $\alpha$ is the power index, and $p_{0}=1.0$ in Eq.3.

Take natural logarithm on both sides of Eq.3, and set $x_{i}=\frac{t}{D}$, the Eq.3 becomes

$\ln \sigma_{\max }=\ln k+\alpha \ln x_{i}$

Where, set $\beta=\ln k$. The maximum bend stress $\sigma_{i}$ at the plate center can be obtained by FEM considering different values of $t / D$. By means of least square method, sum of squares of errors between FEM data and fitting Eq. results is as follows

$$
Q_{e}=\sum_{i}^{n}\left(\ln \sigma_{i}-\ln \sigma_{\max }\right)^{2}=\sum_{i}^{n}\left(\ln \sigma_{i}-\beta-\alpha \ln x_{i}\right)^{2}
$$

In order to solve the minimum value of $Q_{e}$, we take partial derivative respect to $\alpha$ and $\beta$, and set them zero.

$$
\left\{\begin{array}{l}
\frac{\partial Q_{e}}{\partial \beta}=2 \sum_{i}^{n}\left(\ln \sigma_{i}-\beta-\alpha \ln x_{i}\right)(-1)=0 \\
\frac{\partial Q_{e}}{\partial \alpha}=2 \sum_{i}^{n}\left(\ln \sigma_{i}-\beta-\alpha \ln x_{i}\right)\left(-\ln x_{i}\right)=0
\end{array}\right.
$$

Eq. 6 can be simplified as

$$
\left\{\begin{array}{l}
n \cdot \beta+\sum_{i=1}^{n} \ln x_{i} \cdot \alpha=\sum_{i=1}^{n} \ln \sigma_{i} \\
\sum_{i=1}^{n} \ln x_{i} \cdot \beta+\sum_{i=1}^{n}\left(\ln x_{i}\right)^{2} \cdot \alpha=\sum_{i=1}^{n} \ln x_{i} \cdot \ln \sigma_{i}
\end{array}\right.
$$

$\alpha$ and $\beta$ can be solved as

$$
\left\{\begin{array}{c}
\alpha=\frac{\sum_{i=1}^{n} \ln x_{i} \ln \sigma_{i}-\frac{1}{n} \sum_{i=1}^{n} \ln x_{i} \sum_{i=1}^{n} \ln \sigma_{i}}{\sum_{i=1}^{n}\left(\ln x_{i}\right)^{2}-\frac{1}{n}\left(\sum_{i=1}^{n} \ln x_{i}\right)^{2}} \\
\beta=\overline{\ln \sigma_{i}}-\alpha \cdot \overline{\ln x_{i}}
\end{array}\right.
$$

Analysis on data of Tab.1, we can figure out: $\alpha=-1.804, \beta=-1.840$, then

$$
\ln \sigma_{\max }=-1.840-1.804 \ln x_{i}
$$

A significance test for Eq. 9 must be carried out to check its significance. Regression sum of squares and residual sum of squares can be obtained by the above data, $U=26.1, Q_{\mathrm{e}}=0.608122$, $\mathrm{n}=19$.

According the formula of F-test as follows 


$$
F=\frac{U}{Q_{e} /(n-2)} \sim F(1, n-2)
$$

Then $\mathrm{F}=729.6$, for test level of $\alpha=0.01, \quad F_{1-0.01}(1, n-2)=F_{0.99}(1,17)=8.4$. Obviously, $F>F_{0.99}(1,17)$, so $\mathrm{H}_{0}$ is rejected, regression Eq.9 is significant.

Coefficient $k=e^{-1.840}=0.1588$, then, the modified model is as Eq.10

$\sigma_{\text {max }}=0.1588 \cdot\left(\frac{t}{D}\right)^{-1.804}$

Considering common parameter of reinforced soil in practice, Poisson ration $\mu=0.25$, Eq. (11) is translate into the mode of Eq. (1), as follows

$$
\sigma_{\max }=0.04886(3+\mu) p_{0}\left(\frac{D}{t}\right)^{1.804}
$$

Finally, the results of elastic thin plate model, elastic FEM and modified elastic plate model are compared shown as Fig. 4. As seen in Fig. 4, compared with elastic thin plate model the maximum bend stress of the modified elastic plate model is relatively low. The modified elastic plate model is not so conservative like the model of elastic thin plate.

According to Eq.12, the reinforced thickness of the end soils under pressure of water and soil can be calculated by Eq. 13 as

$$
t=K_{0}\left[\frac{k_{0}(3+\mu) p D^{1.804}}{\sigma_{t}}\right]^{\frac{1}{1.804}}
$$

Where, $K_{0}$ is the safety factor of reinforced thickness, the coefficient $k_{0}=0.04886$.

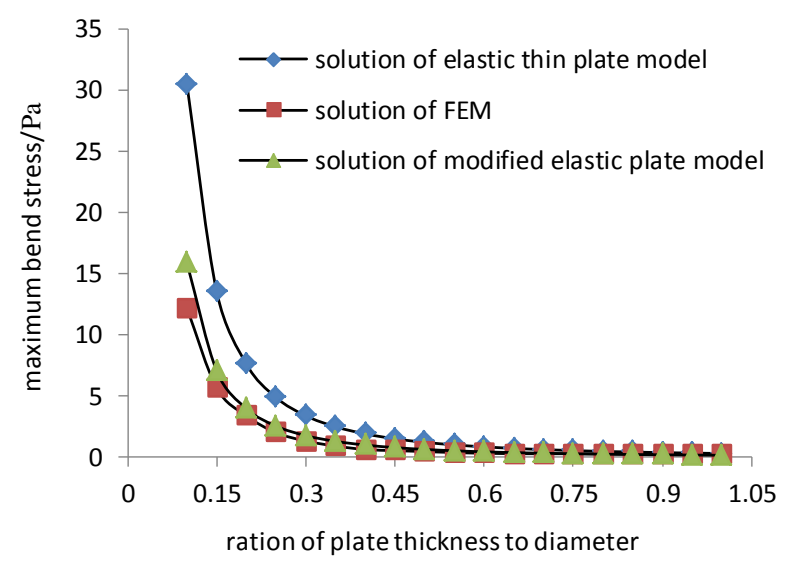

Figure 4. Comparisons of three models results

\section{An Example Analysis}

According to practical engineering, basic parameters of a shield tunnel are taken as: the hole door diameter $\mathrm{D}=6.0 \mathrm{~m}$, cover depth $\mathrm{hs}=20.0 \mathrm{~m}$, ground overload $\mathrm{q}=20 \mathrm{kPa}$, average buoyant unit weight of the soils $\gamma=18.5 \mathrm{kN} / \mathrm{m} 3$ 。 Reinforced by high pressure jet grouting, the strength of reinforced soils is tested by core sampling, we take cohesive force as $\mathrm{Cu}=300 \mathrm{kPa}$, inner friction angel $\varphi \mathrm{u}=350$, unconfined compressive strength $\mathrm{qu}=1500 \mathrm{kPa}$, tensile strength is taken as $10 \%$ of unconfined compressive strength, that is $\sigma_{t}=150 \mathrm{kPa}$.

So water pressure at the hole door center can be get as

$p_{w}=\gamma_{w} h_{w}=230 \mathrm{kPa}$

And soil pressure at the hole door center can be get as

$$
p_{s}=\left(\gamma h_{s}+q\right) \cdot \tan \left(45^{\circ}-\frac{\varphi}{2}\right)=115.3 \mathrm{kPa}
$$


Then resultant pressure at the hole door center can be get as $p=p_{s}+p_{w}=345.3 \mathrm{kPa}$

Taking the parameters into Eq.2 and Eq.13 respectively, the reinforced thickness can be obtained as follows:

According to elastic thin plate model

$$
t=\left[\frac{3(3+\mu) p D^{2}}{32 \sigma_{t}}\right]^{\frac{1}{2}}=5.02 \mathrm{~m}
$$

According to modified elastic plate model

$$
t=\left[\frac{0.04886(3+\mu) p D^{1.804}}{\sigma_{t}}\right]^{\frac{1}{1.804}}=3.43 \mathrm{~m}
$$

In accordance with engineering empirical, we assumes than the safety factor $\mathrm{K} 0$ is 1.5 , the reinforced thickness is $7.54 \mathrm{~m}$ for elastic thin plate model and $5.15 \mathrm{~m}$ for modified elastic plate model respectively. During construction of the engineering the reinforced thickness of the end soils is taken as $6.0 \mathrm{~m}$. It is between the value of elastic thin plate model and the value of modified elastic plate model. It is convinced that the model of elastic thin plate is conservative and not economy to the engineering.

Based on the example's parameters, sensitivity analysis are done, the relationships between the reinforced thickness and water and soil pressure, the tunnel diameter, limit tensile strength of the reinforced soils can be obtained, as shown in Fig. 5 From the figure we can get recognition that, the larger the tunnel diameter, the thicker the reinforced soils needed; the higher the pressure, the thicker the reinforced soils needed and the higher the limit tensile strength, the thinner the reinforced soils needed.
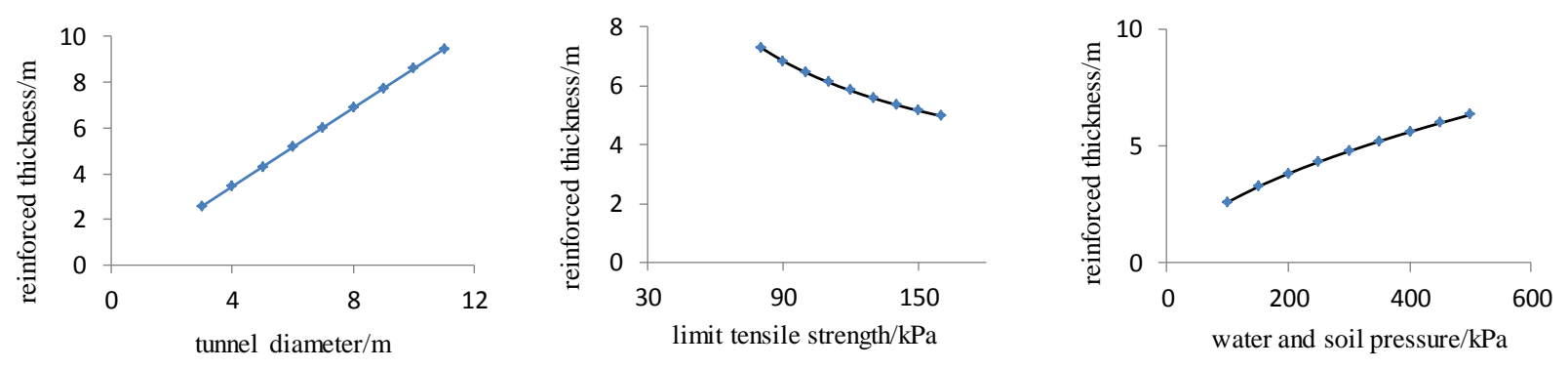

Figure 5. Influencing on the reinforced thickness by varying parameters

The case has manifested that the factors of water and soil pressure, tunnel diameter reinforced methods and its reinforced strength etc should be considered seriously to calculate the reinforced thickness of the end soils. Then the above two models should be used theoretically at the same time. Finally a reinforced thickness is determined by comparing the two models' results and considering similar engineering empirical.

\section{Conclusions}

(1) Based on the existing model of elastic thin plate, a modified model of elastic plate for calculating the reinforced thickness of the end soils. The modified model is fitted by means of elastic FEM data, the model's coefficients is obtained. An example is given to check effectiveness of the model.

(2) The maximum bend stress of the model of elastic thin plate is higher than that of the modified model of elastic plate. It has been manifested by the calculations. The model of elastic thin plate is more conservative and its degree is determined by the ratio of thickness to diameter of the plate $(t / D)$. The finally value of the thickness in practice is between the value of elastic thin plate model and the value of modified elastic plate model. It has proved that the suggested model is 
useful for engineering practices, and extends theoretical methods for calculating the reinforced thickness.

(3) In engineering practices the model of elastic thin plate and the modified model of elastic plate should be used to calculate the reinforced thickness synthetically, comparing the two models' results, considering similar empirical, and the thickness is determined finally.

\section{Acknowledgements}

This paper is sponsored by the Natural Science Foundation of China (No.51478213,51278237).

\section{References}

[1] Y.S. Jiang, C.H. Wang, H. Jiang, et al: Shield Launching and Arriving-Theoretial Study and Engineering Practice on End Reinforcement(People's Communications Publishing House, China, 2011), p.56-185.(in Chinese)

[2] K.Z. Song, M.S. Wang, M. Sun: Chinese Journal of Rock Mechanics and Engineering, Vol. 34 (2015) No.2, p.407-413.(in Chinese)

[3] K.Z. Song, H.C. Hou, G.B. Liu, et al: Jounal of Basic Science and Engineering, Vol. 24 (2016) No.3, p.618-631.(in Chinese)

[4] JJGA High Pressure Jet Grouting Association in Japan: High Pressure Jet Grouting Method(Dongxing Geotechnical Science and Technology Co. Ltd., 1991), p.17-24.(in Japanese)

[5] J.M. Lai, Y. Bai: Geotechnical Engineer, Vol. 6 (1994) No.1, p.11-15.(in Chinese)

[6] D. Wu: Research on Construction Technique and Mechanism of Reinforced Soil for Department and Reception of Large Scale Shield(MS., Tongji University, China 2006), p.36.(in Chinese)

[7] L.M. Yin: Study on the Reinforcement of Soil for Shield Launching in Sandy Pebble Stratum(MS., Central South University, China 2013), p.58.(in Chinese)

[8] F.R. Luo, Y.S. Jiang, H. Jiang: Journal of Engineering Geology, Vol. 19 (2011) No.3, p.364-369.(in Chinese)

[9] Z.X. Xin, J.A. Wang: Study on the Stability of Typical Construction Sections in Underwater Shield Subway Tunnel Projects(MS., University of Science and Technology Beijing, China 2007), p.46.(in Chinese)

[10]Z.X. Xin, J.A. Wang, H.T. Ma, et al: Chinese Journal of Underground Space and Engineering, Vol. 3 (2007) No.3, p.513-518.(in Chinese)

[11]X.P. Hu, M. Sun, J.L. Wang: Tunnel Construction, Vol. 26 (2006) No.5, p.11-13.(in Chinese)

[12] S.Y. Zhu, Z.B. Lin, C.L. Gui: Tunnel Construction, Vol. 32 (2012) No.6, p.788-795.(in Chinese)

[13]Q.Z. Qu: Theory of Elastic Plates(People's Communications Publishing House, China 2000), p.15-18.(in Chinese)

[14] M.Z. Wang: Advanced Theory of Elasticity(Peking University Press, China 2002), p.26-27.(in Chinese) 